\title{
Prospective and Retrospective Timing Processes: Theories, Methods, and Findings
}

\author{
Richard A. Block, Simon Grondin and Dan Zakay
}

\section{1 \\ Introduction}

Although one could date the history of the study of psychological time back to antiquity, with early hominids' experiences and Aristotle's philosophical speculations, that is a matter for historians. The experimental study of time estimation has a history that apparently started with research published in 1868 by Vierordt (Lejeune \& Wearden 2009). This was almost two decades before the widely mentioned beginning of psychological research (Wundt 1886). Also, in the early times of what later became psychology, several interesting theories on timing and time perception were proposed (e.g., Hooke, 1682, as cited in Hintzman 2003; Guyau, 1888; see Michon, Pouthas, \& Jackson, 1988). Beginning especially with theoretical reviews by the philosopher-turnedpsychologist James (1890) and continuing through Fraisse in his famous books, Psychologie du temps (1957/1963) and Psychologie du rythme (1974), the psychology of timing and time perception have blossomed. This is evident in a recent edited volume, also with the title Psychology of time (Grondin 2008b). For a more in-depth historical review, see Hancock and Block (2012), and for a summary of recent review articles, see Block and Grondin (2014).

In the present chapter, we mainly focus on time perception and time estimation (see Block \& Hancock 2013, for an annotated bibliography). The database PsycINFO distinguishes these terms in a slightly overlapping way: The keyword time perception is defined as "perception of duration, simultaneity, or succession in the passage of time." The keyword time estimation is defined as "estimation of duration or passage of time." The MEDLINE, or PubMed, database simply uses the keyword time perception, which is defined as "the ability to estimate periods of time lapsed or duration of time."

In the experimental literature, which we review later, Hicks, Miller, and Kinsbourne (1976) conducted a seminal study. Instead of using James's (1890) descriptions (time in passing and in retrospect), they used the terms prospective and retrospective. In the prospective paradigm, a person is told that time estimation is relevant and important. In the retrospective paradigm, a person 
is misdirected from attending to time, such as with a cover story or a cover task. In everyday life, a time estimate becomes relevant and important when an environmental situation makes demands to respond in a temporally accurate way. Retrospective duration estimates are used in situations such as those involving remembering, eyewitness testimony, and so on.

Researchers have revealed several spans that they think might involve different processes: $100 \mathrm{~ms}$ (Block 1979) to about $1.3 \mathrm{~s}$ (Grondin 2010; Grondin, Laflamme, \& Mioni, 2015), 3 s (Pöppel 1978), or $7 \mathrm{~s}$ (James 189o), and of course even longer. We distinguish between these. We start with brief temporal events, and then we review research on longer episodes. We first detail the importance of different time scales and review procedures, methods, and measures. Then we discuss prospective and retrospective duration judgment processes and findings. We conclude by reviewing research on several related issues, such as temporal illusions and what is usually called prospective memory.

\section{Durations of Temporal Experiences}

If a series of identical visual stimuli occurs at brief interstimulus intervals $(<100$ ms), according to many old experiments, some interesting phenomena occur (see reviews in Block 1979; Patterson 1990). These phenomena were found decades ago and labeled as 'the psychological moment'; all events occurring within this period would be processed as co-temporal (but see Elliott \& Giersch 2016).

However, the experience of duration can be approached differently. It is now known that for the discrimination of auditory brief intervals, the Weber fraction is not constant. When intervals to-be discriminated are longer than circa $1.3 \mathrm{~s}$ (Grondin 2012) the fraction increases-i.e., the discrimination is more difficult (for reviews, see Gibbon, Malapani, Dale, \& Gallistel, 1997; Grondin 2014), just as if a crucial cognitive capacity would be exceeded with long intervals (Grondin et al. 2015). Indeed, there is a possibility to avoid this increase of the Weber fraction. It has been shown that for discriminating brief auditory intervals, it is worth adopting an explicit counting strategy when intervals are longer than $1.2 \mathrm{~s}$ (Grondin, Meilleur-Wells, \& Lachance, 1999).

At longer interstimulus intervals, another phenomenon is experienced, as revealed by several experiments. According to Pöppel (1997), there is a lowfrequency mechanism binding successive events-a kind of temporal integration-into perceptual or action units when these events occur no more than $3 \mathrm{~s}$ apart. This phenomenon is sometimes referred to as 'the subjective present'.

Although these phenomena might result from relatively early analyses of sensory information, other phenomena have been reported as the "flow of time" 
at longer interstimulus intervals in any of several sensory modalities (visual, auditory, or tactual), even with non-identical stimuli (e.g., Gruber \& Block 2013). In other words, some of these temporal experiences appear to be multimodal in origin. These experiments suggest that these temporal phenomena might be a result of sensory persistence, dynamic modal completion, and possibly also conceptual processes.

A longer time-related phenomenon also occurs-possibly up to James's (189o) and other reviewers' identification of $5^{-7} \mathrm{~s}$ as yet another critical period. These might be a result of what are usually now called working memory processes.

Prospective Timing Methods and Processes

Several methodological procedures are used to study the processes involved in timing and time perception. In prospective timing, the participants know in advance that the targeted interval will have to be estimated (such as reproduced). Some authors report four classical methods. In addition to verbal estimation and the method of production, which involve chronometric units, research has been conducted by using other methods, such as the reproduction method and the comparison method (Bindra \& Waksberg 1956; Grondin 2010, 2014; Wallace \& Rabin 1960; Zakay 1993). Figure 2.1 summarizes the main methods for studying time perception.

\subsection{Estimates Relying on Conventional (Learned) Time Units}

In the case of verbal estimations, participants provide a numerical estimation of the duration, using temporal units (seconds or minutes), of a stimulus or a series of stimuli previously presented, such as a flash, sound, series of words or pictures, and so on. Verbal estimates tend to be variable, and they are not suitable for studies involving young children who have not yet learned what seconds or minutes mean. Productions are also based on the use of chronometric units. In the production method, participants are asked to produce, for instance, by tapping twice on the spacebar of a keyboard, to mark the beginning and end of an interval lasting several seconds (Mioni, Stablum, Prunetti, \& Grondin, 2016).

\subsection{Estimates Involving Duration Comparisons}

Young children must learn how to make time estimates using conventional verbal units. However, researchers use other methods to assess time perception. With young children, the reproduction method is often used: A child is shown a stimulus lasting for several seconds, and then is asked to press a button for the 


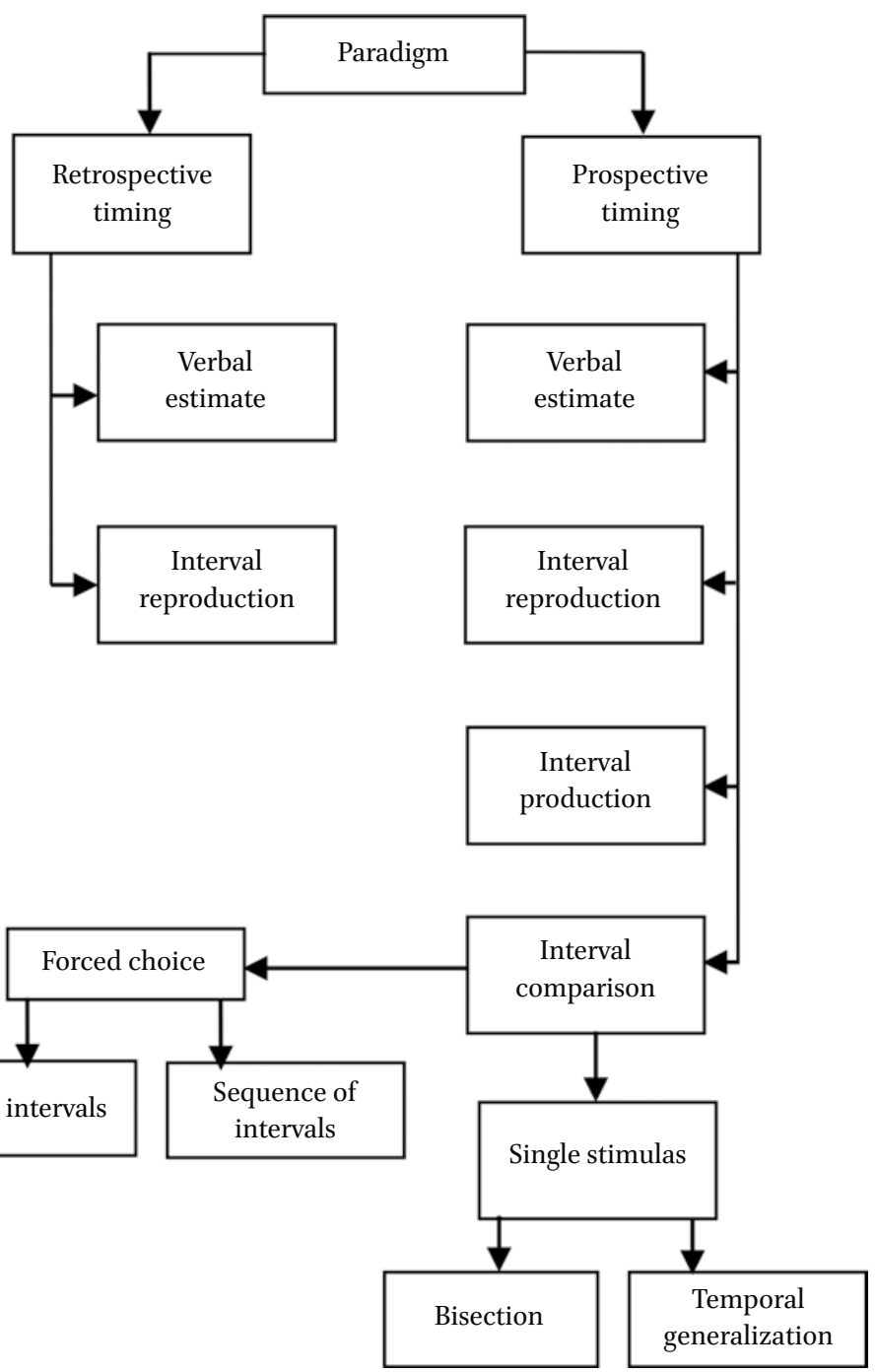

FIGURE 2.1 Summary of the main methods utilized for studying time perception (Adapted from Grondin 2010)

same amount of time that the stimulus appeared (Zakay, 1992a). The wording of these instructions should be adjusted for the age of the child. Also, research using nonhuman animals must use other methods, such as the peak-procedure method, which we do not review here (see, for example, Church 2003; Chapter 6 , this volume).

The method of comparison is a procedure that involves comparing two durations. Using this method, participants are asked to judge the relative duration 
of intervals presented successively, one standard interval and one comparison interval. Each to-be compared interval could be marked by continuous sounds or continuous flashes (filled intervals) or by brief sensory signals marking the beginning and end of each interval (empty intervals). Participants are asked to indicate, such as by pressing an appropriate button, which of two intervals, the first or the second, was shorter or the longer one; or if the second interval was shorter orlonger than the first one. In the comparison method, a reminder method indicates that the standard interval is always presented first (Macmillan \& Creelman 1991): the order of the standard and comparison intervals varies from trial to trial. Other methods may also be used (e.g., Macmillan \& Creelman 1991).

Using the comparison method, with durations of many seconds retrospectively judged, Ornstein (1969) asked participants to make a mark on a second line when given a first line, indicating a comparison of durations. Several researchers have discussed this method (e.g., Block 1974; Grondin 1993; Rammsayer 2014). Recently, Mioni, Stablum, McClintock, and Grondin (2014) emphasized the fact that when slight variations are introduced in reproductions, different results are found. They compared conditions in which participants were instructed either: (a) press only at the end of the interval after having been presented a signal marking the beginning of the interval to-be reproduced, (b) press to start and stop the interval, or (c) press continuously during the interval. The highest accuracy (closest to the target time) was obtained when using keypresses to start and stop the reproduction, but less variability was obtained with the method involving continuous pressing.

\subsubsection{Time-Order Effects}

In psychophysics, presenting intervals successively induces what is called a time-order error (Eisler, Eisler, \& Hellström, 2008; Hellström 1985). Moreover, using a roving or a reminder method also has an impact on duration discrimination: Discrimination is better with the reminder method-that is, with the standard interval kept constant in the first position (Grondin \& McAuley 2009; Hellström \& Rammsayer 2004). The time-order effect is sometimes referred to as a Type-A effect, and the fact of having better performances in the standard-comparison order than in the comparison-standard order is sometimes referred to as a Type-B effect (Bausenhart, Dyjas, \& Ulrich, 2015), or standard position effect (Hellström \& Rammsayer 2015). Time-order errors tend to be negative for relatively short durations - that is, the second duration is judged as longer than the first- but tend to be positive for relatively longer durations, especially those judged in retrospect - that is, the first duration is judged longer than the second (Block 1985). 
To account for the standard position effect, Hellström (1979) proposed a sensation-weighting model. According to this model, in a discrimination task a person compares the scaled subjective difference between the first and the second stimuli (see Hellström \& Rammsayer 2015). Dyjas, Bausenhart, and Ulrich (2014) proposed that the standard position effect can be explained by an internal reference model, which stipulates that discrimination is not based on the internal representation of the standard and comparison intervals, but rather on the internal reference that is built up dynamically from trial to trial during the experiment. In this model, in each experimental trial, participants compare the updated internal reference to the second stimulus.

\subsection{Other Timing Methods}

Another way to investigate processes of prospective timing is to return to Fechner's traditional methods. Kuroda and Hasuo (2014) described ways of using method of limits and of adjustments, in addition of the constant method. For instance, a participant can be presented the standard and comparison intervals, and adjust the comparison interval to make it equal to the standard (method of adjustment). Over a series of trials, the mean adjusted value of the comparison intervals would provide a point of subjective equality (PSE) with the standard, and the variability (standard deviation) of the series of adjusted values could be interpreted as a just noticeable difference (JND; Hasuo, Nakajima, \& Ueda, 2011).

A strict form of the method of limits is not used in time perception studies, but the adaptive procedure could be seen as a variation of this method as it may involve ascending trials and descending trials from specific points above or below threshold. Basically, after each trial, the level of difficult in a discrimination task is adjusted after each trial. With an adaptive procedure, an experimenter should decide what the magnitude of the changes are after a correct and after an incorrect response, when a series of trials ends, how many series of trials are necessary, and how the threshold is operationally defined and calculated (Macmillan \& Creelman 1991). In the classical adaptive method called the staircase procedure, the steps up and down of the comparison stimulus are changed by a fixed amount, and a series of trials could end after a certain number of changes or a certain number of trials. There are several other adaptive procedures, including parameter estimation by sequential testing and the procedures based on a Bayesian procedure or maximum likelihood (Shen 2013). The adaptive procedure usually provides a good approximation of a threshold value with a reasonable number of trials and is often used in duration discrimination studies (e.g., Rammsayer 2014). 
With the constant method, a series of comparison intervals is selected and one of these, in a random order from trial to trial, is presented after the standard. After multiple presentations of each comparison intervals, a psychometric function can be drawn, plotting the probability of responding that the comparison interval is longer than the standard on the $Y$-axis, as a function the length of the comparison intervals on the $X$-axis (Grondin 2008a, 2010). On a psychometric function, the PSE is given by the value on the $X$-axis corresponding $50 \%$ on the $Y$-axis (see Figure 2.2). It is classical to define the difference threshold as the difference, divided by 2 , between the $X$ values corresponding to $75 \%$ and $25 \%$ on the $Y$-axis. These two percentages correspond to mid-point between perfect discrimination (o or 100\%) and random responses $(50 \%)$. Another frequent way of expressing the difference threshold is to estimate one standard deviation on the psychometric function (Killeen \& Weiss 1987).

The use of the constant method and of a psychometric function raises the question of the model adopted for drawing the function through the data points.

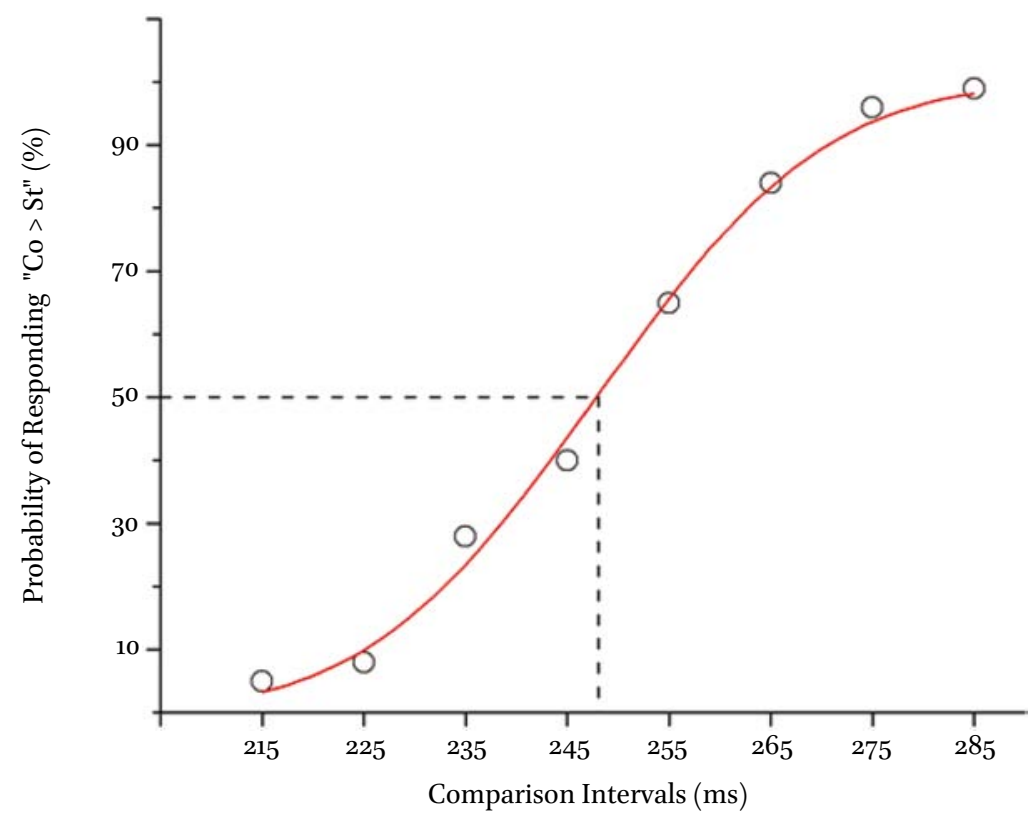

FIGURE 2.2 Psychometric function used for estimating the difference threshold with the constant method. "Co > St" means that the comparison interval is judged as longer than the standard ( $250 \mathrm{~ms}$ ). The model for fitting the data points in this example is the cumulative normal distribution, and the dashes indicate the point of subjective equality (Adapted from Grondin 2008a) 
In psychology, it is typical to assume that a phenomenon is distributed normally, and, thus, a Gaussian model is adopted (cumulative normal distribution; see for instance Laflamme, Zakay, Gamache, \& Grondin, 2015). Among the other models, Macmillan and Creelman (1991) proposed the logistic and the Weibull functions, and the reader will also find the use of a pseudo-logistic function in the time perception literature (Grondin 2001a; Killeen, Fetterman, \& Bizo, 1997).

In a variant of the constant method, called the single-stimulus method, a participant makes a judgment after each interval presentation. This involves assigning the interval to one of two categories, short or long; there is no presentation of the standard on each trial (see for instance Grondin, Laflamme, \& Gontier, 2014, Experiment 3; Kuroda, Grondin, Miyazaki, Ogata, \& Tobimatsu, 2016). A classical method in the animal timing literature, called the bisection method, is a widely used variant of this method in human timing studies (Mioni, Meligrana, Grondin, Perini, Bartolomei, \& Stablum, 2015a; Mioni, Zakay, \& Grondin, 2015b; Penney, Gibbon, \& Meck, 2008; Chapter 4, this volume). With this method, a series of intervals are selected and the shortest and the longest intervals (referred to as standards) of this series are first presented several times. In the following trials, each interval of this series is presented several times, in a random order, and on each trial the interval should be categorized as closer to one of the two standards. As for the constant method, a psychometric function can be drawn from these data. There are many other methods in the study of animal timing, including temporal generalization, which is also used in the human timing literature (Wearden \& Lejeune 2006). With this method, the mid-point interval in a series of intervals is first presented several times and in subsequent trials, participants indicate whether the interval presented is or is not of the same length as the standard.

Depending on the specific field of interest, specific variants of methods can be used. Researchers interested in motor behavior and timing have used a production method, which is indeed most often a task where a participant first listen to a series of isochronous sounds and eventually tries to synchronize finger tapping with the sound; at some point, there is no more sound but the participant continues to tap at the same pace. The dependent variable of interest is the variability of the inter-tap intervals in the continuous phase, and sometimes the mean inter-tap intervals. It is possible to distinguish the part of variance, in the overall observed variance, belonging to the motor system (implementation of the tap) and the part belonging to the internal timekeeping system (Wing \& Kristofferson 1973).

Finally, researchers more interested in rhythm perception than interval timing often use duration discrimination methods, but instead of presenting 
single intervals (a single standard or a single comparison interval), multiple successive standard or comparison intervals are presented. Increasing the number of intervals generally leads to improved discrimination (for a review, see ten Hoopen, Miyauchi, \& Nakajima, 2008). Beyond four presentations, in the auditory modality, there is not much improvement to expect (ten Hoopen, van den Berg, Memelink, Bocanegra, \& Boon, 2011); and, in the visual modality, the gain with multiple presentations depends on the duration under investigation and on presenting or not the standard and comparison intervals in continuity (Grondin 2001a).

Much evidence reveals that attention to time is involved in prospective timing. Block (1990) criticized this concept because of the descriptive nature of the term, without any experimental or theoretical work on underlying processes. Later, Block (2003), for example, came to clarify and accept the term. He and others suggested that it involves what is now called recursive reminding (e.g., Hintzman 2004). If a person is asked to indicate when an experimenterspecified duration has elapsed, he or she often thinks: "Is it time now?" Every time that the person has that thought, it retrieves a time-dated memory of the previous occurrence. How often that happens depends on secondary-task attentional demands: If a person has to perform another cognitive task, the recursive reminding process is interrupted. Thus, duration productions lengthen, for example.

However, this explanation does not completely reveal the reason why cognitive load affects prospective duration judgments. The attentional-gate model (AGM; see, for example, Zakay \& Block 1997) provides that kind of explanation. In this model, attention to time affects prospective duration judgments. A classical explanation of prospective timing is based on an internal-clock device made of a pacemaker emitting pulses, and of a counter accumulating these pulses, the perceived duration being proportional to the number of pulses accumulated. The AGM proposed by Zakay and Block (Figure 2.3; see Block \& Zakay 2008; Zakay \& Block 1997, for a description) determines the number of pulses, with more pulses being accumulated when more attention is allocated to the passage of time, and less to a nontemporal secondary task (in the case of a dual-task paradigm).

Perhaps both ideas are needed, recursive reminding to explain what it means when a person attends to time, and attentional gating to explain dual-task interference effects. Additional evidence on prospective duration judgments 


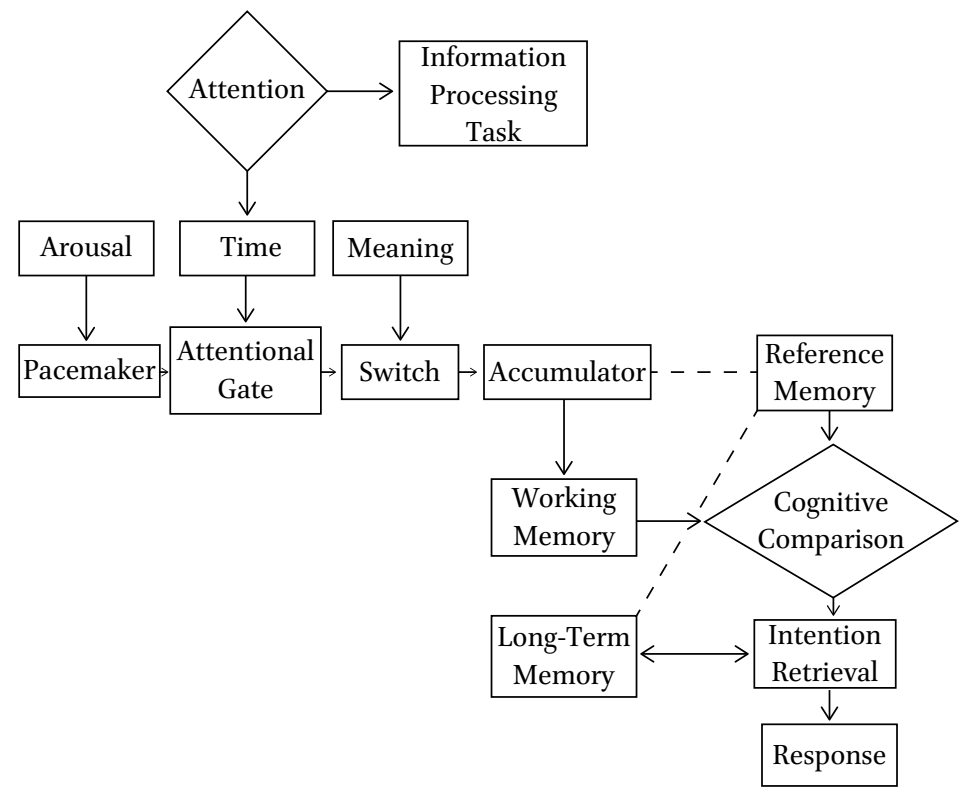

FIGURE 2.3 The attentional-gate model of prospective timing (from Block \& Zakay 2008; Zakay \& Block 1997)

comes from many experiments that have been reviewed in two major metaanalyses (Block, Hancock, \& Zakay, 2010; Block \& Zakay 1997) of studies using durations greater than $3 \mathrm{~s}$. These findings reveal that variables involving cognitive load affect prospective timing. Mainly, these are response demands (active vs. passive), attentional demands (divided or selective vs. unitary), and processing difficulty (difficult vs. easy). With any of these cognitive demands,prospective duration judgments made with the production method lengthened and verbal estimates decreased, for example.

Zakay (1992b, 2015)) reported research on temporal relevance and temporal uncertainty as variables that affect prospective timing. If an interval is relevant to a person's current concern or if the person is uncertain about when an interval will end, prospective temporal productions lengthen. This model supports a model of prospective timing that emphasizes attention. Forexample, waiting intervals are perceived as longer than same clock-time intervals without waiting, because while waiting time is a major concern and the end of the waiting is not certain. Zakay (2005) showed that when timing is done concurrently with a nontemporal task, the duration of the interval is perceived to be longer when a person is instructed to treat timing as a primary rather than as a secondary task. 
In another duration judgment paradigm, a participant is not informed in advance that time has to be estimated. Experiments using this retrospective paradigm are far less numerous than those using the prospective paradigm, probably because only one duration estimate may be obtained before the participant is aware that time judgments are of interest. Sometimes, at the onset a cover story or cover task might be used to lead participants to think that duration is not relevant (Grondin \& Laflamme 2015). Retrospective judgments concern the remembered duration of past episodes, and they are based much more on memory than on attention to time. Meta-analytic findings (Block, Hancock, \& Zakay, 2010; Block \& Zakay 1997) reveal that variables involving cognitive load do not affect retrospective judgments. The important variables are segmentation (e.g., high-priority events or contextual interruptions) and other variables that affect memory encoding and retrieval. A contextual change memory model is implicated: If a person is able to remember more changes in context, retrospective duration judgments lengthen (Block \& Reed 1978).

Two main methods have been most frequently used to study retrospective timing: the method of reproduction and the method of verbal estimation. When intervals under investigation are not too long, it is reasonable to consider the possibility to ask a participant to reproduce the duration. In such a case, this means that during the encoding phase (the interval to be reproduced), the participant is not informed that the duration (of the activity for instance) will have to be reproduced. For very long intervals, it is not realistic to adopt the reproduction method. Using verbal estimation is more practical. The problem that occurs with the verbal estimation is that people tend to round up their judgments to the nearest second if intervals are relatively brief, to the nearest 5 or 10 seconds if intervals last at least one minute, and to the nearest halfminute, or even minute, if the intervals last several minutes. One feature of retrospective judgments is that people should not be aware of the need to judge duration. Consequently, after completing a single trial, participants are aware of the importance of the duration of an activity or event. One way of collecting more than one judgment per participant is to ask to complete a series of activities before asking for duration judgments. Such a strategy was adopted by Boltz (1995), which involved a series of brief melodies $(<15 \mathrm{~s})$ to be learned before reproducing their duration (Experiment 1 ) and the presentation of long films (Experiment 2). Brown and Stubbs (1988) used a multiple-activity approach. They presented musical excerpts lasting 96 to $570 \mathrm{~s}$. Boltz presented brief videotape sequences. Grondin and Plourde (2007) asked participants to complete five cognitive tasks (e.g., counting backward, recalling names of animals in 
alphabetical order) lasting 2-8 minutes, before asking for a verbal estimate of the duration of each of these tasks.

Researchers using retrospective timing are usually interested in the accuracy of judgments, not by the variability of estimates as is often the case for prospective timing. Limiting an investigation to a single trial actually makes it difficult to study the variability issue. A way to approach the problem is to ask not only for a verbal estimate of the activity, but also for a window within which the duration is certainly included. For example, a researcher may ask for the maximum and minimum duration of the activity (Bisson \& Grondin 2013; Grondin \& Plourde 2007; Tobin, Bisson, \& Grondin, 2010; Tobin \& Grondin 2012). The difference between the maximum and minimum could be interpreted as an uncertainty window, of a measure of variability.

Like many other perceptual processes, time perception suffers from illusions that result from the processes underlying prospective and retrospective timing. Temporal illusions occur when the perception of duration of an interval do not faithfully represent the objective (clock-time) duration of that interval.

A well-known illusion is the filled-duration illusion: Empty intervals are perceived to be shorter or longer than filled intervals, which objectively endure exactly the same clock time. The direction of the illusion depends on the paradigm. If timing is done prospectively, then empty intervals, which do not demand many attentional resources for information processing, will be perceived as longer than filled intervals, which demand many attentional resources (e.g., Wearden, Norton, Martin, \& Montford-Bebb, 2007). The opposite is the case regarding retrospective estimates. In this case, empty intervals are perceived as shorter than same clock time compared to filled intervals.

Thus, the perceived duration of an interval depends on cognitive load during the interval (Block et al. 2010.) This contradicts the essential characteristics of physical time. For example, it is often said that time flies when a person is having fun. The reason is that while having fun, attention is focused on the "fun" aspects (e.g., an attractive film) and not on time. Thus, the same clock-time interval will be perceived as longer when a person suffers instead of having fun. This is, of course, another illusion.

The "watched-pot" phenomenon is another temporal illusion. When a person waits for something to occur (when the water in a pot will boil), the main concern is time (when will this happen), and as a result most attentional resources are focused on time. This results in a longer temporal experience as compared to a regular interval (Block, George, \& Reed, 1980). 
An everyday situation in which people experience this illusion is when they have to wait for someone to come or some event to happen. Waiting intervals are perceived as longer than same clock-time intervals, without waiting. There are many more temporal illusions, most of them are prospective and reflect the dependency on attentional resources. The AGM provides a good explanation for that.

Temporal-illusions are an example for the dependency of subjective timing processes on measurement methods, interval durations, and other factors. For example, Hasuo, Nakajima, Tomimatsu, Grondin, and Udea (2014) found that for short intervals $(40-520 \mathrm{~ms})$ the illusion was more likely to occur with magnitude estimation than with the method of adjustment. The magnitude of the illusion increased as the interval duration lengthened. Taking a somewhat philosophical perspective, one may ask if not all temporal experience, including the flow of time itself, is actually an illusion (Gruber \& Block 2013). Subjective durations are rarely identical with objective durations.

\section{Temporal Dating of Memories}

For centuries, dating to Aristotle, philosophers have thought that time is intimately related to memory. Theorists such as James (1890) and Hooke (1705/1969; see Hintzman 2003) proposed ideas on time and memory in the brain. These earliest ideas were reviewed by Hintzman (2003) and others (Block \& Zakay 2008). Now, researchers have revealed how such temporal contiguity-proximity in time-functions (Hintzman 2016). Hintzman concluded that there is little or no evidence of temporal organization by contiguity per se. He said that research does not support the hypothesis that memory is not organized by time or by the principle of contiguity. Then he also elaborated on the present status of these ideas. In our view, time perception is mainly automatic only in some kinds of judgments that do not require voluntary attention. Automatic encoding might apply only to temporal dating of events, not necessarily to the dual-task interference seen in prospective duration estimation. Prospective duration estimates are based on attentional processes, as the AGM suggests. Temporal dating of specific memories is based on other processes, which involve long-term memory.

Another interesting topic, which relates to processes involved in prospective and retrospective duration judgments, concerns prospective memory, which 
has also been called prospective remembering, or timing the future. These tasks involve intending to perform a time-based or an event-based action at some future time or occasion (Block \& Zakay 2006; Graf \& Grondin 2006; Labelle, Graf, Grondin, \& Gagné-Roy, 2009; Mioni \& Stablum 2014). For example, what role does temporal memory of past events serve in remembering to perform future actions? If people think about something that might likely occur (perhaps with what is called stimulus-independent mentation, or daydreaming), what time-related processes are involved?

Time-based and event-based prospective remembering processes are similar to those implicated in prospective and retrospective duration judgments, respectively. In timed-based tasks, participants are asked to make a response when they think that an experimenter-specified duration has elapsed; this is similar to a prospective duration estimate. In event-based tasks, people are asked to respond when a particular event (such as presentation of an animal word, or in everyday life, meeting a specific person) is encountered.

Time-based prospective memory tasks are similar to those involved in laboratory studies on prospective duration judgments, such as using the method of production. While is performing another task, the person must signal when a specified time interval (such as $30 \mathrm{~s}$ ) has ended. The findings reveal that, such as in prospective duration judgments, attentional demands of the nontemporal task affect these processes. In everyday life, time-based tasks are often performed successfully by using reminder methods, such as calendars or electronic notes.

Event-based prospective memory tasks rely on the intent to respond in a certain way when a situation is encountered. Meeting a person or seeing a particular kind of event occur may lead to automatic retrieval of the intent. Of course, this is also somewhat likely to lead to failures to remember the previous intent.

\section{Summary}

In this chapter, we reviewed the history, methods, and current status of psychological research on timing and time perception, focusing mainly on prospective and retrospective judgments of time. Time perception varies as a function of duration, or interstimulus interval. Different phenomena arguably occur at about $100 \mathrm{~ms}, 1.3 \mathrm{~s}, 3 \mathrm{~s}, 5^{-7} \mathrm{~s}$, and longer. Various methods are used, including those that require knowledge of conventional time units as well as others that do not. The latter have been used in studies of nonhuman animals and young children. Prospective time judgments, which involve a situation in which the estimation of durations is relevant and important, 
are affected by other information-processing demands. Retrospective duration judgments, on the other hand, depend mainly on retrieval of memories from the time period, and those are mainly affected by contextual encoding and retrieval processes. Other kinds of time-related phenomena occur in prospective memory situations, for example. Time-based remembering processes are similar to those of prospective timing, especially using the production method. Event-based remembering relies on memory processes similar to those involved in retrospective duration judgments. We did not review evidence on the many brain areas and processes involved in psychological time, mainly because the evidence is still unclear; future researchers should focus on that issue in order to deepen the understanding of these processes.

\section{References}

Bausenhart, K.M., O. Dyjas, \& R. Ulrich (2015). Effects of stimulus order on discrimination sensitivity for short and long durations. Attention, Perception, \& Psychophysics, 77, 1033-1043.

Bindra, D., \& H. Waksberg (1956). Methods and terminology in the studies of time estimation. Psychological Bulletin, 53, 155-159.

Bisson, N., \& S. Grondin (2013). Time estimates of Internet surfing and video gaming. Timing \& Time Perception, 1, 39-64.

Block, R.A. (1974). Memory and the experience of duration in retrospect. Memory \& Cognition, 2, 153-16o.

Block, R.A. (1979). Time and consciousness. In Underwood, G. \& R. Stevens (Eds.), Aspects of consciousness: Vol. 1. Psychological issues (pp. 179-217). London: Academic Press.

Block, R.A. (1985). Contextual coding in memory: Studies of remembered duration. In Michon, J.A. \& J.L. Jackson (Eds.), Time, mind, and behavior (pp. 169-178). Berlin: Springer-Verlag.

Block, R.A. (1990). Models of psychological time. In Block, R.A. (Ed.), Cognitive models of psychological time (pp. 1-35). Hillsdale, NJ: Erlbaum.

Block, R.A. (2003). Psychological timing without a timer: The roles of attention and memory. In Helfrich, H. (Ed.), Time and mind II: Information processing perspectives (pp. 41-59). Göttingen, Germany: Hogrefe \& Huber.

Block, R.A., \& S. Grondin (2014). A review of recent reviews on the psychology of time. Frontiers in Psychology: Perception Science, 5, 1-3.

Block, R.A., \& P.A. Hancock (2013). Time perception. Oxford Bibliographies. [0123. $\mathrm{xml}$ ?rskey=rykwK8\&result=146]. 
Block, R.A., \& M.A. Reed (1978). Remembered duration: Evidence for a contextualchange hypothesis. Journal of Experimental Psychology: Human Learning and Memory, 4, 656-665.

Block, R.A., \& D. Zakay (1997). Prospective and retrospective duration judgments: A meta-analytic review. Psychonomic Bulletin \& Review, 4, 184-197.

Block, R.A., \& D. Zakay (2006). Prospective remembering involves time estimation and memory processes. In Glicksohn, J. \& M.S. Myslobodsky (Eds.), Timing the future: The case for a time-based prospective memory (pp. 25-49). RiverEdge, $\mathrm{NJ}$ :World Scientific.

Block, R.A., \& D. Zakay (2008). Timing and remembering the past, the present, and the future. In Grondin, S. (Ed.), Psychology of time (pp. 367-394). Bingley, England: Emerald.

Block, R.A., E.J. George, \& M.A. Reed (1980). A watched pot sometimes boils: A study of duration experience. Acta Psychologica, 46, 81-94.

Block, R.A., P.A. Hancock, \& D. Zakay (2010). How cognitive load affects duration judgments: A meta-analytic review. Acta Psychologica, 134, 330-343.

Boltz, M.G. (1995). Effects of event structure on retrospective duration judgments. Perception \& Psychophysics, 57, 1080-1096.

Brown, S.W., \& D.A. Stubbs (1988). The psychophysics of retrospective and prospective timing. Perception, 17, 297-310.

Church, R.M. (2003). A concise introduction to scalar timing theory. In Meck, W.H. (Ed.), Functional and neural mechanisms of interval timing (pp. 3-22). Boca Raton, FL: CRC Press.

Dyjas, O., K. Bausenhart, \& R. Ulrich (2014). Effects of stimulus order on duration discrimination sensitivity are under attentional control. Journal of Experimental Psychology: Human Perception and Performance, 40, 292-307.

Eisler, H., A. Eisler, \& A. Hellström (2008). Psychophysical issues in the study of time perception. In Grondin, S. (Ed.). Psychology of time (pp. 75-110). Bingley, U K: Emerald Group Publishing.

Elliott, M.A., \& A. Giersch (2016). What happens in a moment. Frontiers in Psychology: Perception Science, $7(6), 1-8$.

Fraisse, P. (1967/1973). Psychologie du temps [Psychology of time] (2nd ed.). Paris: Presses Universitaires de France.

Fraisse, P. (1974). Psychologie du rythme [Psychology of rhythm]. Vendome, France: Presses Universitaires de France.

Gibbon, J., C. Malapani, C.L. Dale, \& C. Gallistel (1997). Toward a neurobiology of temporal cognition: Advances and challenges. Current Opinion in Neurobiology, 7 , 170-184.

Graf, P., \& S. Grondin (2006). Time perception and time-based prospective memory. In Glicksohn, J. \& M.S. Myslobodsky (Eds.), Timing the future: The case for a time-based prospective memory (pp.1-24). River Edge, $\mathrm{NJ}$ : World Scientific. 
Grondin, S. (1993). Duration discrimination of empty and filled intervals marked by auditory and visual signals. Perception \& Psychophysics, 54, 383-394.

Grondin, S. (2001a). Discriminating time intervals presented in sequences marked by visual signals. Perception \& Psychophysics, 63, 1214-1228.

Grondin, S. (2001b). From physical time to the first and second moments of psychological time. Psychological Bulletin, 127, 22-44.

Grondin, S. (2008a). Methods for studying psychological time. In Grondin, S. (Ed.). Psychology of time (pp. 51-74). Bingley, U K: Emerald.

Grondin, S. (2008b). Psychology of time. Bingley, u K: Emerald.

Grondin, S. (2010). Timing and time perception: A review of recent behavioral and neuroscience findings and theoretical directions. Attention, Perception \& Psychophysics, $72,561-582$.

Grondin, S. (2012). Violation of the scalar property for time perception between 1 and 2 seconds: Evidence from interval discrimination, reproduction, and categorization. Journal of Experimental Psychology: Human Perception and Performance, 38, $880-890$.

Grondin, S. (2014). About the (non)scalar property for time perception. In Merchant, H. \& V. de Lafuente (Eds.), Advances in Experimental Medicine and Biology. Neurobiology of interval timing (vol. 829, pp. 17-32). New York: Springer.

Grondin, S., \& V. Laflamme (2015). Stevens's law for time: A direct comparison of prospective and retrospective judgments. Attention, Perception, \& Psychophysics, 77, 1044-1051.

Grondin, S., \& J.D. McAuley (2009). Duration discrimination in crossmodal sequences. Perception, 38, 1542-1559.

Grondin, S., \& M. Plourde (2007). Judging multi-minute intervals retrospectively. Quarterly Journal of Experimental Psychology, 6o, 1303-1312.

Grondin, S., G. Meilleur-Wells, \& R. Lachance (1999). When to start explicit counting in time-intervals discrimination task: A critical point in the timing process of humans. Journal of Experimental Psychology: Human Perception and Performance, 25, 993-1004.

Grondin, S., V. Laflamme, \& E. Gontier (2014). Effect on perceived duration and sensitivity to time when observing disgusted faces and disgusting mutilation pictures. Attention, Perception \& Psychophysics, 76, 1522-1534.

Grondin, S., V. Laflamme, \& G. Mioni (2015). Do not count too slowly: Evidence for a temporal limitation in short-term memory. Psychonomic Bulletin \& Review, 22, $863-868$.

Gruber, R.P., \& R.A. Block (2013). The flow of time as a perceptual illusion. Journal of Mind and Behavior, 34, 91-100.

Guyau, A. (1890). Le genese de l'idee au temps. Felix Alcan (ed. A Fouilee).

Hancock, P.A., \& R.A. Block (2012). The psychology of time: A view backward and forward. American Journal of Psychology, 125, 267-274. 
Hasuo, E., Y. Nakajima, \& K. Ueda (2011). Does filled duration illusion occur for very short time intervals? Acoustical Science \& Technology, 32, 82-85.

Hasuo, E., Y. Nakajima, E. Tomimatsu, S. Grondin, \& K. Ueda (2014). The occurrence of the filled duration illusion: A comparison of the method of adjustment with the method of magnitude estimation. Acta Psychologica, 147, 111-121.

Hellström, Å. (1979). Time errors and differential sensation weighting. Journal of Experimental Psychology: Human Perception and Performance, 5, 460-477.

Hellström, Å. (1985). The time-order error and its relatives: Mirrors of cognitive processes in comparing. Psychological Bulletin, 97, 35-61.

Hellström, Å., \& T.H. Rammsayer (2004). Effects of time-order, interstimulus interval, and feedback in duration discrimination of noise bursts in the 50- and 1000-ms ranges. Acta Psychologica, 116, 1-20.

Hellström, Å., \& T.H. Rammsayer (2015). Time-order errors and standard-position effects in duration discrimination: An experimental study and an analysis by the sensation-weighting model. Attention, Perception, \& Psychophysics, 77, 2409-2423.

Hicks, R.E., G.W. Miller, \& M. Kinsbourne (1976). Prospective and retrospective judgments of time as a function of amount of information processed. American Journal of Psychology, 89, 719-730.

Hintzman, D.L. (2003). Robert Hooke's model of memory. Psychonomic Bulletin \& Review, 10, 3-14.

Hintzman, D.L. (2004). Judgment of frequency versus recognition confidence: Repetition and recursive reminding. Memory \& Cognition, 32, 336-350.

Hintzman, D.L. (2016). Is memory organized by temporal contiguity? Memory \& Cognition, 44, 365-375.

Hooke, R. (1969). The posthumous works of Robert Hooke: With a New Introduction by Richard S. Westfall. New York: Johnson Reprint Corp. (Original work published 1705) ten Hoopen, G., R. Miyauchi, \& Y. Nakajima (2008). Time-based illusions in the auditory mode. In Grondin, S. (Ed.). Psychology of time (pp.139-187). Bingley, U K: Emerald.

ten Hoopen, G., S. van den Berg, J. Memelink, B. Bocanegra, \& R. Boon (2011). Multiplelook effects on temporal discrimination within sound sequences. Attention, Perception, \& Psychophysics, 73, 2249-2269.

James, W. (1890). The principles of psychology. New York: Holt.

Killeen, P.R., \& N.A. Weiss (1987). Optimal timing and the Weber function. Psychological Review, 94, 455-468.

Killeen, P.R., J.G. Fetterman, \& L.A. Bizo (1997). Time's causes. In Bradshaw, C.M. \& E. Szabadi (Eds.), Time and behavior: Psychological and neurobehavioral analyses (pp. 79-131). Amsterdam: Elsevier.

Kuroda, T., \& E. Hasuo (2014). The very first step to start psychophysical experiments. Acoustical Science \& Technology, 35, 1-9.

Kuroda, T., S. Grondin, M. Miyazaki, K. Ogata, \& S. Tobimatsu (2016). The kappa effect with only two visual markers. Multisensory Research, 29(8), 703-725. 
Labelle, M.-A., P. Graf, S. Grondin, \& L. Gagné-Roy (2009). Time-related processes in time-based prospective memory and in time-interval production. European Journal of Cognitive Psychology, 21, 501-521.

Laflamme, V., D. Zakay, P.-L. Gamache, \& S. Grondin (2015). Foreperiod and range effects on time interval categorization. Attention, Perception, \& Psychophysics, 77, 1507-1514.

Lejeune, H., \& J. Wearden (2009). Vierordt's the experimental study of the time sense (1868) and its legacy. European Journal of Cognitive Psychology, 21, 941-96o.

Macmillan, N.A., \& C.D. Creelman (1991). Detection theory: A user's guide. New York: Cambridge University Press.

Michon, J.A., V. Pouthas, \& J.L. Jackson (1988). Jean-Marie Guyau: Life and ideas. In Michon, J.A., V. Pouthas \& J.L. Jackson (Eds.), Guyau and the idea of time (pp. 19-36). Amsterdam: North-Holland.

Mioni, G., \& F. Stablum (2014). Monitoring behaviour in a time-based prospective memory task: The involvement of executive functions and time perception. Memory, 22, 536- 552 .

Mioni, G., F. Stablum, S.M. McClintock, \& S. Grondin (2014). Different methods for reproducing time, different results. Attention, Perception, \& Psychophysics, 76, 675-681.

Mioni, G., L. Meligrana, S. Grondin, F. Perini, L. Bartolomei, \& F. Stablum (2015a). The effects of the facial expression of emotions on time perception in patients with Parkinson's disease. Journal of the International Neuropsychological Society, 21.

Mioni, G., D. Zakay, \& S. Grondin (2015b). Faster is briefer: The symbolic meaning of speed influences time perception. Psychonomic Bulletin \& Review , 22, 1285-1291.

Mioni, G, F Stablum., E Prunetti., \& S Grondin. (2016). Time perception in anxious and depressed patients: A comparison between time reproduction and time production tasks. Journal of Affective Disorders, 196, 154-163.

Ornstein, R.E. (1969). On the experience of time. Harmondsworth, England: Penguin.

Patterson, R. (1990). Perceptual moment models revisited. In Block, R.A. (Ed.), Cognitive models of psychological time (pp. 85-100). Hillsdale, nj: Erlbaum.

Penney, T.B., J. Gibbon, \& W.H. Meck (2008). Categorical scaling of duration bisection in pigeons (Columba livia), mice (Mus musculus), and humans (Homo sapiens). Psychological Science, 19, 1103-1109.

Pöppel, E. (1978). Time perception. In Held, R., H.W. Leibowitz \& H.-L. Teuber (Eds.), Handbook of sensory physiology (Vol. 8, pp. 713-729). Berlin: Springer-Verlag.

Pöppel, E. (1997). A hierarchical model of temporal perception. Trends in Cognitive Sciences, 1, 56-61.

Rammsayer, T. (2014). The effects of type of interval, sensory modality, base duration, and psychophysical task on the discrimination of brief time intervals. Attention, Perception, \& Psychophysics, 76, 1185-1196. 
Shen, Y. (2013). Comparing adaptive procedures for estimating the psychometric function for an auditory gap detection task. Attention, Perception, \& Psychophysics, 75, 771-780.

Tobin, S., \& S. Grondin (2012). Time perception is enhanced by task duration knowledge: Evidence from experienced swimmers. Memory \& Cognition, 4o, 1339-1351.

Tobin, S., N. Bisson, \& S. Grondin (2010). An ecological approach to prospective and retrospective timing of long durations: A study involving gamers. PLoS ONE, 5(2), eg271.

Wallace, M., \& A. Rabin (1960). Temporal experience. Psychological Bulletin, 57, 213-235. Wearden, J.H., \& H. Lejeune (2006). Temporal generalization in humans. Journal of Experimental Psychology: Animal Behavior Processes, 18, 134-144.

Wearden, J.H., R. Norton, S. Martin, \& O. Montford-Bebb (2007). Internal clock processes and the filled-duration illusion. Journal of Experimental Psychology: Human Perception and Performance, 33, 716-729.

Wing, A.M., \& A.B. Kristofferson (1973). Response delays and the timing of discrete motor responses. Perception \& Psychophysics, 14, 5-12.

Wundt, W. (1886). Eléments en psychologie physiologique. Paris: Alcan.

Zakay, D. (1992a). The role of attention in children's time perception. Journal of Experimental Child Psychology, 54, 355-371.

Zakay, D. (1992b). On prospective time estimation, temporal relevance and temporal uncertainty. In Macar, F., V. Pouthas, \& W.J. Friedman (Eds.), Time, action and cognition: Towards bridging the gap (pp. 109-117). New York: Kluwer Academic/Plenum.

Zakay, D. (1993). Time estimation methods: Do they influence prospective duration estimates? Perception, 22, 91-101.

Zakay, D. (2005). Timing is a natural secondary task. Proceedings of the annual meeting of the International Society for Psychophysics (Fechner Day), Traverse City, USA.

Zakay, D. (2015). The temporal-relevance temporal-uncertainty model of prospective duration judgment. Consciousness and Cognition, 38, 182-19o.

Zakay, D., \& R.A. Block (1997). Temporal cognition. Current Directions in Psychological Science, $6,12-16$. 